\title{
Reality shifting: psychological features of an emergent online daydreaming culture
}

\author{
Eli Somer ${ }^{1}$ (I) $\cdot$ Etzel Cardeña ${ }^{2} \cdot$ Ramiro Figueiredo Catelan $^{3} \cdot$ Nirit Soffer-Dudek $^{4}$ \\ Accepted: 25 October 2021 \\ (c) The Author(s), under exclusive licence to Springer Science+Business Media, LLC, part of Springer Nature 2021
}

\begin{abstract}
Reality shifting (RS) is a trendy mental activity that emerged abruptly following the flare-up of the COVID-19 pandemic in 2020 and seems to be practiced mainly by members of the post-millennial generation. RS, described as the experience of being able to transcend one's physical confines and visit alternate, mostly fictional, universes, is discussed by many on Internet platforms. One RS forum boasts over 40,000 members and RS clips on some social media platforms have been viewed over 1.7 billion times. The experience of shifting is reportedly facilitated by specific induction methods involving relaxation, concentration of attention, and autosuggestion. Some practitioners report a strong sense of presence in their desired realities, reified by some who believe in the concrete reality of the alternate world they shift to. One of the most popular alternate universes involves environments adopted from the Harry Potter book and film series. We describe the phenomenology of $\mathrm{RS}$ as reported online and then compare it to related phenomena such as hypnosis, tulpamancy, dissociation, immersive and maladaptive daydreaming, and lucid dreaming. We propose a theoretical model of interactive factors giving rise to RS, and conclude that it is an important, uninvestigated emerging phenomenon and propose future research directions.
\end{abstract}

Keywords Daydreaming $\cdot$ Fantasy $\cdot$ Reality shifting $\cdot$ Hypnosis $\cdot$ Maladaptive daydreaming

On January 30, 2020, the World Health Organization (WHO) declared the Coronavirus an international public health emergency. In the shadow of the COVID-19 pandemic and the months spent indoors due to global lockdowns and restrictions, mentions of a new solitary mental activity called reality shifting (RS) grew exponentially on several online social platforms such as Amino, Reddit, TikTok, YouTube, and Wattpad. Figure 1 shows the relatively stable Google search volume for the term "Stress Reduction" (in

Etzel Cardeña, Ramiro Figueiredo Catelan and Nirit Soffer-Dudek contributed equally to this work

Eli Somer

somer@ research.haifa.ac.il

1 University of Haifa, Haifa, Israel

2 Present Address: CERCAP, Department of Psychology, Lund University, Lund, Sweden

3 Present Address: Center for Maladaptive Daydreaming and Emotion Dysregulation Research, Institute of Psychiatry, Federal University of Rio de Janeiro, Rio de Janeiro, Brazil

4 Present Address: Ben-Gurion University of the Negev, Beer-Sheva, Israel red), unchanged following the WHO designation of COVID19 as an International Emergency. In contrast, "Reality Shifting" was a relatively uncommon search term until the WHO declaration but rose sharply shortly after it.

$\mathrm{RS}$ is commonly described by video creators and bloggers as the experience of being able to transcend their physical confines and visit alternate, mostly fictional, universes. They reportedly employ specific meditative techniques to facilitate their ostensible "quantum" journeys. After the pandemic plateaued and even after it started declining, the practice still seemed to have millions of followers, many of whom share their experiences and offer tips to improve the desired voyages. One community on Reddit called DimensionJumping has close to 42,200 members (Reddit, r/dimensionjumping, n.d.). The explosive popularity of this mental activity among TikTok users can be gauged by monitoring relevant hashtags. The pertinent hashtag \#realityshifting on TikTok has accumulated over 706 million views (TikTok, \#realityshifting, n.d.-a) while \#shiftingrealities has accrued over 1.8 billion views (TikTok \#shiftingrealities, n.d.-b). The term has also received mainstream media coverage, as exemplified by a recent story in the Washington Post (Andrews, 2021). Here is how a member described her practice online: 


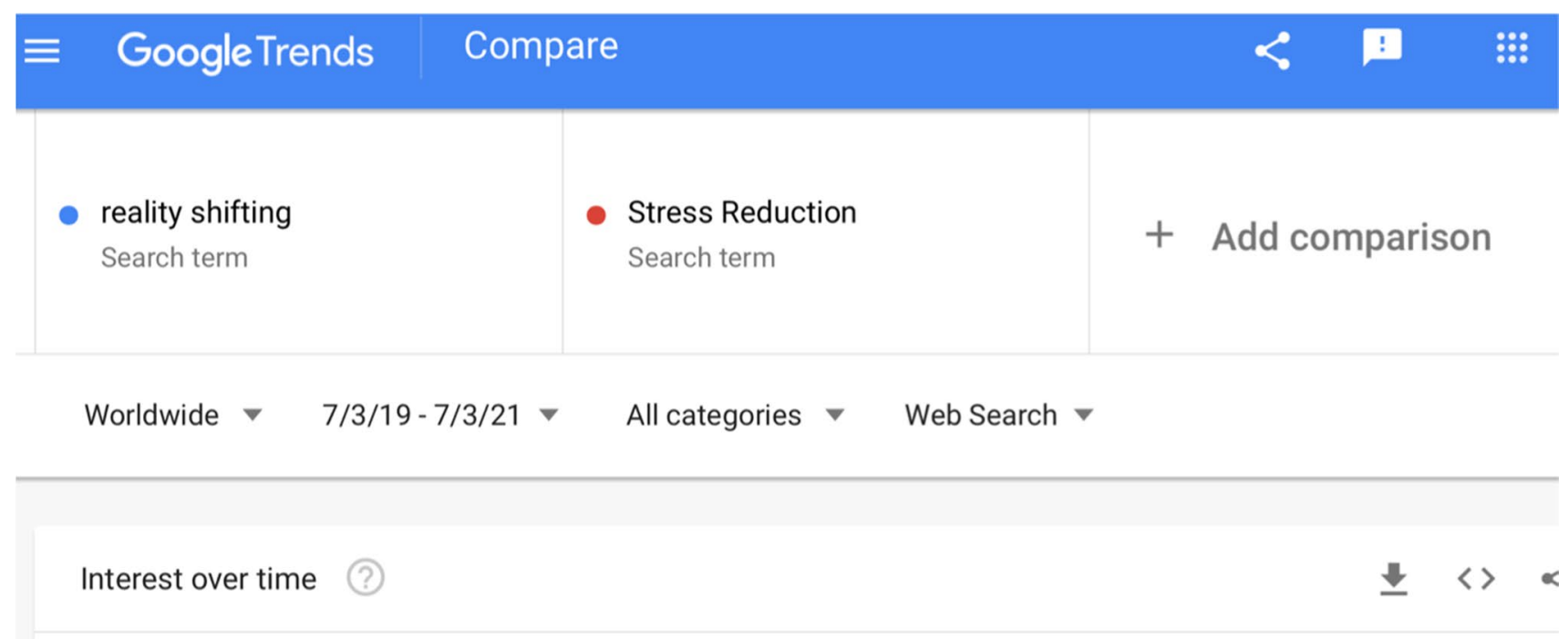

January 30, 2020: COVID-19 declared an International Emergency

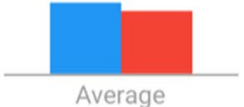

Average

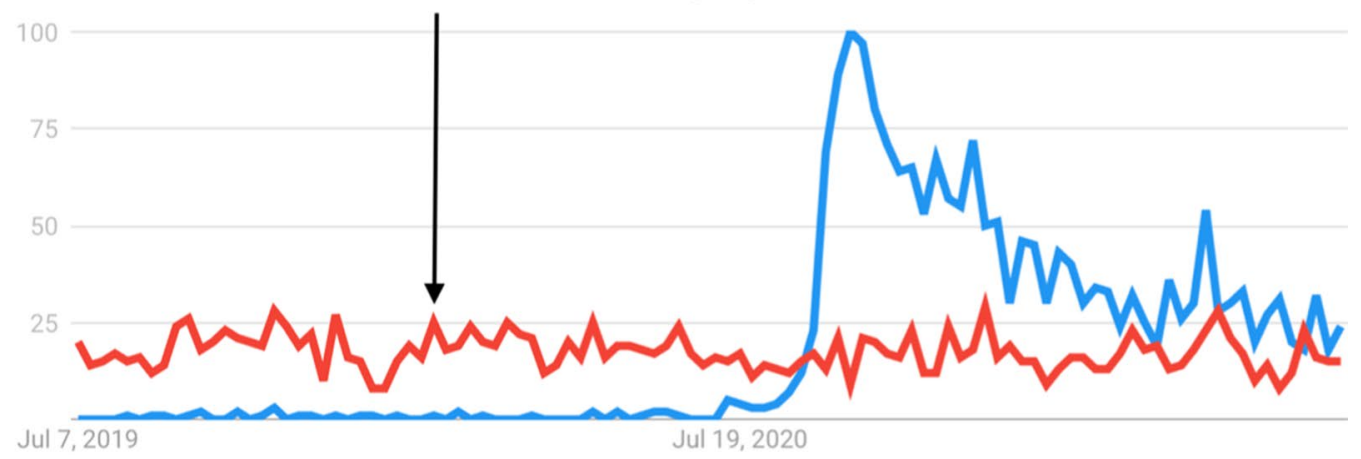

Fig. 1 A Google Trends analysis of the relative worldwide search volume of the terms "stress reduction" and "reality shifting" between January 7, 2019, and July 7, 2021

Note: Google Trends shows normalized data. This means that when one looks at search interest over time for a topic, that interest is presented as a proportion of the chosen searched topics on Google dur-

Shifting is a very strange experience. It's like an extremely vivid dream, yet it's more real than any dream I've ever had. Before I plan on shifting, I write myself a script in the notes app on my phone, in which I plan exactly what happens in the desired reality. This makes it easier to visualize exactly what I want to happen - so I might script that I want to go to Hogwarts and for Draco to be my boyfriend, or that he will flirt with me.

The purpose of this paper is to describe the socially important yet scientifically unevaluated practice of RS, discuss its phenomenology and psychological features, and compare it with relevant phenomena such as tulpamancy, lucid dreaming, hypnosis, and maladaptive daydreaming. RS is described by the moderator of $r /$ shiftingrealities, a Reddit ing that period and at that location. Figure 1 shows the global search interest for the terms "Reality Shifting" and "Stress Reduction" as a proportion of all searches on these topics on Google worldwide before, during, and following the outbreak of the COVID-19 pandemic.

RS community with over 37,000 members, as "sending your consciousness to other realities. You can go to any reality you want, whether it be $2 \mathrm{D}$ or 3D. There are different explanations for why this happens, such as the multiverse theory and the idea that this is a transliminal experience. No matter which explanation you believe in, it is possible to go to another world, whether real or not" (u/Automoderator, 2021).

A core explanation espoused by some practitioners of $\mathrm{RS}$ as to why it works is based on the multiverse theory, first advocated by physicist Hugh Everett III's many-worlds interpretation of quantum mechanics. Multiverse theory tenets are rooted in extrapolations of modern cosmology, quantum theory, and theory of relativity, which posit that a countless range of universes may be possible with different sets of low energy hypothetically present in our world, 
composing an infinite web of different realities coexisting simultaneously (Linde, 2017). The theory does not posit, however, that individuals can create their own realities (cf. Barrow et al., 2004) and is considered unfalsifiable and thus questionable by some in the mainstream physics community (Kragh, 2009).

A review of RS posts on social media indicated that some individuals seemed to be convinced that the desired reality (DR) they shift to was just as real as their current reality (CR), featuring protagonists with independent feelings, emotions, and memories. Some of those who experience RS reported on social media that their practice was first described in a declassified CIA document titled "Analysis and Assessment of Gateway Process." (McDonnel, 1983). In the document's 29 pages, the writer, Lieutenant Colonel Wayne McDonnell, outlined a method involving hypnosis and binaural audio stimulation designed to achieve equal amplitude and frequency of EEG patterns in both brain hemispheres. Its purpose seemed to have been the induction of out-of-body states capable of time travel, remote viewing, and, ultimately, information gathering (for a review on outof-body experiences, see Cardeña and Alvarado, 2014).

Our description, comparison, and analysis of RS consists of our observations concerning the characteristics of this novel occurrence, based on our review of the voluminous online accounts of RS. We do not presume to offer demographic estimations or prevalence appraisals, which can be generated by subsequent systematic research.

\section{Induction Methods}

To experience their travel to another DR, RS practitioners employ several methods. Online descriptions of shifting often entail a blend of the following preparation steps:

- A 5-10-min meditation, often mindfulness-based, aimed at clearing the mind to focus it on the shifting process.

- A detailed script with a comprehensive guide for the DR experience, which can include information about preferred looks, traits, friends, family, or surroundings, and can take either virtual or physical (written/visual) forms. Scripts can include information about characters, languages spoken, perfume worn, along with notes on how the passage of time differs between CR and DR or ways to return to the CR. Other suggestions often scripted include a safe word that can bring the person quickly back to the CR, an affirmation that one cannot be traumatized in the DR, or a declaration that one cannot get too attached to one's DR.

General statements/affirmations are commonly used to enhance DR experiences. For example:
- I am in my desired reality and I can feel it.

- I am in my desired reality and my desired reality follows my script.

- I can shift my consciousness to the reality I desire whenever I want to.

Some RS practitioners report listening to "subliminals," affirmations related to the desired DR, sped up and layered with music and ambient noise. "Subliminals" are available on YouTube and SoundCloud (e.g., Leviathan, 2020) and are said to persuade the person into believing that they can successfully achieve a chosen goal. "Subliminals" are also reported to help shift to the DR and shape it.

Following the preparation phase, various methods to induce the shifting are described. Some of the most popular are:

- The Raven Method, perhaps the most prevalent one, in which the person is instructed to lie in a starfish position and count to 100 while "subliminals" are playing and the individual is reciting positive affirmations between numbers.

- The Alice in Wonderland method involves people lying on their back and imagining sitting against a tree until someone from their DR runs past them. At that point, it is suggested to chase that character until one "falls down the rabbit hole" and finds a key to one's DR.

- The Pillow Method includes writing down affirmations on a piece of paper and repeating them before bed, making sure to sleep with the paper under the pillow. This technique seems to improve the RS experience upon awakening.

- In the Elevator Method, individuals are to imagine themselves in an elevator going to the DR on the top floor. Energy levels purportedly intensify as the elevator ascends past the floors. When the energy is high enough, the elevator doors open to the DR.

- The Lifa App is an imaginary (not a CR) app that one can script. Many different versions of the app are reported online (e.g., -peachy, 2019). Most Lifa Apps allow the editing of appearance, DR scripts, and DR objects like food. Lifa Apps can be created individually or downloaded as a template. There are many visuals for the Lifa app on Pinterest (e.g., Pax, 2020).

\section{Phenomenology}

The experience of transitioning into the DR is protean and may involve different sensorial features. Many participants in this mental activity report numbness, tingling, heaviness or weightlessness, and floating sensations. Others describe muscle tension, sensations of spinning, rocking, falling, 
twitching/jerking, and shortness of breath. The experience of RS may also feature increased heart rate, dry mouth, itchiness, seeing flashing lights, tiredness/drowsiness, a buzzing sensation, ears ringing, hearing voices, hot/cold rushes, eyes involuntarily opening, and feeling longing/nostalgia.

Just before experiencing an entrance into an alternate reality, some voyagers report seeing the same number sequences, which they refer to as "Angel Numbers." These are, allegedly, codes believed to have specific numerological significance. Upon entering the DR, many individuals report sensing the sounds, sights, and smells of the destination universe. DR worlds are individualized and idiosyncratic, but RS fandoms seem to feature trendy themes as well.

\section{Popular Desired Realities}

The following worlds seem to be preferred RS environments:

\section{Harry Potter Environments}

Hogwarts School of Witchcraft and Wizardry This is the fictional British boarding school of magic for students aged eleven to eighteen and the primary setting for the first six books in J. K. Rowling's Harry Potter series.

Draco Malfoy Many young females report joining Draco Malfoy as his girlfriend. Draco is a fictional character from the Harry Potter series, characterized as a cowardly bully who tricks and hurts people to get what he wants, a cunning user of magic.

\section{Shadowhunters}

This world is based on a TV series that follows a young woman who finds out on her 18th birthday that she is not who she thinks she is, but rather comes from a long line of Shadowhunters, human-angel hybrids who hunt down demons and deal with the struggle of forbidden love.

\section{Star Wars}

The Star Wars pop-culture universe depicts the adventures of characters from a remote galaxy in which humans and humanoid species of aliens co-exist with robots who may assist them in their daily routines. All living things create an energy field that binds the galaxy together and is called "the Force." Through training and meditation, living things can enhance the Force and perform such feats as psychokinesis, precognition, telepathy, and manipulation of physical energy.

\section{Other Popular RS Universes}

There are many sources for DR, including Japanese comic worlds such as Anime, Hetalia, My Hero Academia, and Manga; the science fiction series Avatar; a mermaid environment; being a member of a werewolf family; and alternate relationships and families. These contents usually come from movies, books, TV series, and video games.

\section{Motivation}

Spontaneous online testimonies and talkbacks concerning the motivation for RS vary, but an impressionistic analysis of random reports reveals that participants tend to experience joy and elation during their RS experiences. Some reports suggest that RS may serve as a way of coping with hardships in the CR. For example:

I wanted to shift because I thought it would be nice to escape my current reality because it is exam season and I am feeling a little stressed out now, that is why I want to shift right now just [so] that I could escape the pressures of my current reality and get a moment in my desired reality where I can feel stress-free.

The following is also representative of YouTube comments:

Its [sic] always been my dream to go to Hogwarts but I just thought it was never possible also I HATE most of my cr so I was just escaping reality by watching Harry Potter Movies also I am a Draco simp so it has always been my dream and this gives me so much hope thank you so much.

\section{Reification}

Our survey of RS social media platforms identified numerous posts by individuals who seemed to treat their mental experiences as though they were real events involving actual environments. For instance, in response to a question on the Reddit RS community asking "Can I tell the people in my DR that I shifted there? Is that bad?" the online community moderator responded: "...you can technically tell them, think about how that information would be received. They'd probably think you were crazy because their reality is just as real to them as your CR is to you...".

\section{Respawning}

Respawning is a radical manifestation of the escapist psychological role RS can play. Some RS practitioners are motivated to permanently sever their ties with the $\mathrm{CR}$ and live in 
an alternate DR of choice, opting to leave their "clones" (i.e., someone who will continue interacting in the CR) behind and leaving the CR forever (e.g., Madame Lovi, 2003).

\section{Individual Differences}

Not everyone can shift their realities. Online RS communities feature numerous posts by individuals who had been trying, unsuccessfully, to implement RS induction techniques such as the following: "I'm trying to shift for two weeks almost now and nothing's happening. I see angel numbers I get all the symptoms, but I don't shift. I don't know how to reach my dr, I've tried all methods possible, but nothing is working. I feel like crying because I' $m$ trying so hard and there are no results. I just feel so demotivated and useless: (()".

This new young persons' subculture bears a resemblance to other mental activities that may shed light on the ontology of RS. We now review researched psychological phenomena relevant to RS and analyze their differences and similarities.

\section{Phenomena Related to RS}

\section{Tulpamancy}

Starting around 2009, online communities started reporting the practice of "tulpamancy," referring to the creation of "tulpas" or animated, responsive beings. The concept stems from, according to David-Neel (1929/1971), the Tibetan Buddhist belief that an autonomous being or object can be created by the mind (Borges's 1944 short story Las Ruinas Circulares is a literary rendition of the idea). The term has been adopted by proliferating online communities. Tulpas are experienced as distinct individuals that serve as companions sharing the practitioners' bodies (Laursen, 2019). Tulpamancy is viewed by its advocates as a way to overcome loneliness and mental suffering. Like the RS internet communities, online tulpa communities provide manuals for the creation of these internal protagonists. For example, the Hands-On Tulpa Creation Guide (https:/tulpa.fandom.com/ wiki/EnEllDee\%27s_Hands-On_Tulpa_Creation_Guide) provides the stages necessary for developing a tulpa. They include: designing the tulpa's form and personality; creating a "wonderland": the tulpa's physical milieu; forcing: meditation-style activities aimed at projecting oneself into a wonderland to develop or interact with a tulpa; creating the form, for example, by envisioning a $3 \mathrm{~d}$ model of the desired tulpa's form; and giving the tulpa a personality, for example by imagining the traits on rays of light that go into their head.

At least two studies have evaluated tulpamancy practice and mental health. Veissière (2016) mentioned that most respondents in an interview were young (between 19 and 23 years old), white urban, articulate, imaginative, with very limited social interactions, lonely, and scoring high in the Tellegen Absorption Scale (TAS; Tellegen and Atkinson, 1974, which will be discussed further below). They mentioned social anxiety as a reason to undertake the practice and had high percentages of various diagnoses including Asperger's syndrome (25\%) and attention deficit hyperactivity disorder $(21 \%)$ in comparison with population norms. Respondents noted that tulpa practice had improved their condition. Similar results were reported from an online survey, including mention of conditions improving because of tulpa and the use of meditation and/or hypnosis (Isler, 2017).

Tulpamancy and RS share striking similarities but are also distinct in several ways.

In terms of similarities, both involve the experience of multiple realities that negate the axiomatic singularity of identity/mind. For example, RS entails the existence of a "clone," a piece of one's consciousness that stays behind in the CR body as a person shifts. The clone is said to look, think, act, and talk like the person who shifted. Interestingly, both mental activities are cultivated among online communities that act as participatory spaces in which supernatural or trans-human possibilities are experimented with (Natale and Pasulka, 2019). These online communities, while seemingly unusual, might offer insights into fundamental mechanisms of human needs in the framework of cyberspace anonymity, accessibility, and speed (Stendel et al., 2020).

Yet, the two phenomena differ in some key features. RS involves the creation of alternate "innerscapes": artefactual representations of the mind as a spatially extended world (Bernini, 2018). In contrast, tulpas are essentially the adult version of imaginary companions, a natural phenomenon among children associated with a range of positive developmental outcomes (Fernyhough et al., 2019). Although there is no evidence that tulpamancy is psychopathological per se, the literature suggests that people with dissociative disorders are more likely to report having imaginary friends (McLewin and Muller, 2006). Additionally, unlike the parallel alternate RS worlds that individuals believe they are transported to, tulpas accompany persons in their real worlds and are often described as a way to experience a meaningful relationship and a fluid individuality by challenging cultural assumptions about the superiority of singular identity and by advocating a plurality of identity as a normal psychological preference (Laursen, 2019).

\section{Lucid Dreaming}

In lucid dreams (LD) one is cognizant of the fact that one is dreaming while remaining asleep (LaBerge, 2014). This state seems to involve increases in rapid gamma band activity in frontotemporal areas of the brain (Dresler et al., 2012; 
Voss et al., 2009, 2014), suggesting that this state has wakelike characteristics such as insight and thought monitoring (obtained through self-reports while dreaming) alongside sleep features (Filevich et al., 2015; Voss et al., 2018). Although many people have experienced lucidity spontaneously at least once in their lifetime (Aviram and SofferDudek, 2018), its actual incidence is quite rare, estimated at $1-2 \%$ of dreams, according to two studies (in LaBerge, 2014). LD can also be deliberately induced, and is considered desirable by many (e.g., Johnson, 2020; Laberge, 2009) because it entails steering dream events into desired experiences such as flying or conversing with a deceased loved one or fictional character (Schädlich and Erlacher, 2012). Philosophers and religious writers throughout history have mentioned that "awakening within a dream" may enable transcending the limited world of the senses (Price and Cohen, 1988).

Both LD and RS are cultivated online with dedicated cyber-forums meant to optimize this anomalous experience, in which unfeasible coveted goals are attained while dreaming. Moreover, enhancing statements used to induce RS bear similarity to motivational affirmations used by some LD enthusiasts to achieve lucidity. Examples of autosuggestion techniques to facilitate lucidity include telling oneself that tonight one will have a lucid dream and planning and imagining what one will do in the lucid dream (LaBerge and Rheingold, 1990; Paulsson and Parker, 2006). Despite these similarities, the two self-directed consciousness states differ in other ways. LD usually involves becoming conscious of dreaming during an ongoing nocturnal dream, which is not predetermined by the dreamers, although they may exert some control once they become lucid (Laberge, 2014). Notably, advanced lucid dreamers may also enter an LD directly from waking, i.e., "fall asleep consciously" (LaBerge and Rheingold, 1990), and perhaps the dream content may be more controlled. Still, LD will probably never be as scripted, detailed, and controlled as RS, because they are experienced within the context of a sleeping brain.

\section{Hypnosis}

The RS induction techniques and resultant alterations of consciousness have several parallels to hypnosis. RS can be considered a particular form of self-hypnosis with respect to induction, scripting, spontaneous phenomenology, and individual differences regarding who can have the experience. Both phenomena (and various others) can be discussed as forms of believed-in imaginings, "as-if" socially constructed (or social poetics) narratives treated as perceptual (de Rivera and Sarbin, 1998). Concerning induction, the RS initial meditation (or self-hypnosis) would have the same role of focusing attention and getting rid of extraneous concerns before focusing on specific suggestions, as occurs in most hypnotic inductions (Barber, 1984). The detailed scripts, including safe words, correspond to detailed hypnotic suggestions for a particular purpose (Hammond, 1988), and the enhancing statements can be seen as similar to hypnotic egostrengthening suggestions (Hartland, 1971).

As for the phenomenology of RS before entering the DR, similar somatic sensations and body image changes have been reported spontaneously by highly hypnotizable individuals during a "light" hypnosis stage and before entering states involving imaginal worlds experienced as "real" (Cardeña, 2005). Bodily sensations and perceptions such as shortness of breath, ears ringing, and hearing voices are, however, not common in hypnosis. Because hearing voices is also associated with dissociative or psychotic conditions (Moskowitz et al., 2018), although it is not necessarily pathological (Bentall, 2014), it is important to ascertain how frequent they are, what are its associated features, and whether there is a particular profile to those RS practitioners who report them.

Like reports from online RS communities, the responsivity to hypnotic suggestions shows strong individual differences. Approximately $10 \%$ of individuals respond to hypnotic suggestions with similar behaviors, experiences, and underlying neurophysiological dynamics as they would respond to the objects or experiences suggested (e.g., Kosslyn et al., 2000), approximately $10 \%$ do not respond at all or minimally to suggestions, and around $80 \%$ are between those poles (Barnier and Council, 2010). An individual's level of responding generally remains stable across decades (Piccione et al., 1989). The group of high hypnotizables is heterogeneous, with at least two groups, one exhibiting more imaginal experiences and the other ("dissociative") a sense of lack of mental control and problems with memory (e.g., Terhune and Cardeña, 2010). The level of hypnotic responsiveness does not have a substantial association with the "Big Five" personality traits but shows moderate to small correlations with constructs that pertain to the propensity to be involved experientially and experience alterations of consciousness, such as absorption and self-transcendence (e.g., Cardeña and Terhune, 2014).

One final relevant point to RS is that although hypnotizability, in general, is not related to psychopathology, a subgroup of extremely high hypnotizable individuals, which Herbert Spiegel (1974) described as "Grade 5 syndrome," may show related dysfunction due to their suggestibility, including extreme compliance and suspension of critical judgment. This may be partly due to the subgroup of "dissociative highs" who report a higher history of stress/trauma and pathological fantasy, and a greater sense of involuntariness than the subgroup of "imaginative highs" (Terhune et al., 2010).

In sum, there are many reasons to think of RS as following self-hypnotic techniques and having similar effects, 
although outside of a hypnotic context. In general, the use of hypnosis is not problematic, but it carries risks, which will likely be enhanced by unsupervised practice. Thus, it is important to research the effect of RS for different types of followers across time (cf. Cardeña and Terhune, 2009).

\section{Absorption, Dissociation, and Fantasy Proneness}

High hypnotizability has a consistent correlation with absorption (Roche and McConkey, 1990). Absorption (Tellegen and Atkinson, 1974) is a personality trait showing a tendency to allocate total attention to a stimulus, resulting in a heightened sense of the reality of the attentional object, imperviousness to distracting events, and an experiential rather than conceptual set. Those succeeding in initiating RS are presumably high in absorption in that they can narrow their attention and ignore external distractions, and can experience their DR as a vivid and life-like alternate reality.

The main assessment measure for absorption, the TAS (Tellegen and Atkinson, 1974), includes various mystical, emotional, perceptual, and synesthetic experiences, rendering the construct a representation of both an expansion and a restriction of the field of consciousness (Tellegen, 1992 in Kihlstrom, 2017). A pertinent and closely related construct is the empirically derived dissociative factor of "absorption and imaginative involvement" from the Dissociative Experiences Scale (DES; Carlson and Putnam, 1993), henceforth dissociative absorption (DA). Although it is defined similarly to Tellegen and Atkinson's absorption — as the tendency to allocate total attention to a stimulus, becoming completely engrossed in it and thus oblivious to other stimuli (Carlson and Putnam, 1993; Soffer-Dudek et al., 2015), DA is also distinct. Theoretically, this type of absorption prioritizes the narrowing or restricting (thus, dissociative) part of absorption and does not include religious/cosmic (e.g., feeling that the mind could envelop the whole world) or synesthetic (e.g., associating music to colors) experiences. Empirically, DA is correlated more strongly with other dissociative measures than with the TAS; also dissociative measures, including DA, are more specifically associated with a disconnection from the self than the TAS (Bregman-Hai et al., 2020). This dissociative characteristic may be relevant to RS, as will be discussed further below.

Part of the DA construct includes self-reported heightened imaginative abilities, to the point of believed-inimaginings. Evidence shows that among healthy individuals, those high in DA can experience vivid visual imagery (Bregman-Hai et al., 2018), evidencing that high scores on this factor do not necessarily indicate a cognitive deficit. These data confirm the existence of individual differences in imaginal-absorptive states, in a similar vein to differences in hypnotizability. Those high in DA also tend to report that they can act on "auto-pilot" and not remember their action, as their attention was focused on their daydreaming while performing complex actions (Soffer-Dudek and Somer, in press). This dual consciousness state may contribute to a decreased sense of personal agency (Bregman-Hai et al., 2020). Could this be the psychological mechanism behind the experience of "clones"? Clones, purportedly, inhabit the bodies of RS practitioners when they shift to their DR, and some shifters describe their CR bodies as behaving "on autopilot." As mentioned above, DA is associated with a disconnection from the sense of self, and is, indeed, closely related to dissociative depersonalization (i.e., estrangement from, or unfamiliarity with, one's own body or self). The close connection between DA and depersonalization is probably caused by the tendency to focus attention inwards, at the expense of being attuned with the external world (SofferDudek and Somer, in press). Those practicing RS to escape their CR may experience high levels of dissociation and a sense of disconnection with their bodies and their surroundings, in favor of a socially acceptable (within the RS subculture) focus on their internal world. Moreover, experimenting with an alternate sense of identity (in the DR) may either lead to - or be driven by - a dissociative experience of multiplicity of identities.

There is a discussion in the literature about a possible constellation of personality traits and experiences of fantasy proneness (FP) in some individuals, whose daydreams and imaginative activities are particularly lucid and vivid. Fantasy-prone individuals tend to be more highly hypnotizable than average and have vivid imaginal experiences, hence this trait may also be relevant to explain RS. A meta-analysis showed that this construct relates moderately to strongly with absorption, dissociation measures (which typically involve items measuring absorption), schizotypy (which is not necessarily pathological, e.g., Holt et al., 2020), and excessive daydreaming, but only weakly with depression and anxiety (Merkelbach et al., 2021). Terms such as "fantasies," "addicted to fantasizing," and "fantasy-prone personalities" have already been used to describe people with FP, whose spectrum ranges from healthy to pathological (Wilson and Barber, 1982). Some studies have shown that the presence of FP is connected to the experience of parapsychological phenomena, the presence of paranormal beliefs, and to reports of various anomalous experiences (Bartholomew et al., 1991; Cardeña and Alvarado, 2014; Dasse et al., 2015; Merkelbach et al., 2021).

\section{Immersive and Maladaptive Daydreaming}

Daydreaming is a common cognitive activity in which the individual gets involved with fantasies and visual imagery not necessarily elicited by current external stimuli (Klinger, 2009). When someone daydreams, their attention is often directed to episodic, ongoing, and 
stimulus-independent thoughts, which may emerge as an alternative stream of consciousness, "projecting" themselves into a certain visual scene as if it were happening at the moment (Song and Wang, 2012). This counterfactual aspect is like many RS accounts and demands investigation. Daydreaming may also require one's agency to engage in mental introspection voluntarily to produce experiential representations (Dorsch, 2015), which also resembles the active and intentional feature of inducing RS.

Immersive daydreaming (ID) is a form of fantasizing described as an intense absorption in rewarding imagination content that involves a strong sense of presence and is associated with kinesthesia and exposure to evocative music (West and Somer, 2020). ID often entails a highly complex and structured fantasy activity, with the creation of unrealistic scenarios, including the development of imagined characters (Somer et al., 2021). Observation of online reports on DRs reveals fanciful features. The experienced DRs show powerful immersive properties conveying the impression that voyagers into the DR may experience an intense sense that they are literally "entering" a different world, often based on preexisting fiction stories.

Maladaptive daydreaming (MD) is a pathological form of ID because of the distress it causes and the associated impairments in important areas of functioning, such as social interaction, work, and study (Somer, 2002). Many persons who identify themselves as maladaptive daydreamers refer to it as an addictive behavior (Soffer-Dudek et al., 2021). Whether RS can cause distress or functional impairment has not been researched at this point.

In reviewing RS posts on social media, we noticed mentions of movement in some RS practices when some fantasized activity is physically acted out. As noted above, kinesthesia such as in pacing, gesturing, or mouthing is typical of ID and MD (Bigelsen et al., 2016; Jopp et al., 2019; Soffer-Dudek et al., 2021; Soffer-Dudek and Somer, 2018) and probably plays a role in the induction and maintenance of this activity. A hypothesized function of movement in MD is the induction of the fantasy and its enhancement through the physical enactment of the imagined scene (Somer, 2002). It is also possible that the repetition generates a form of selfhypnosis facilitating the immersive-absorptive state. Many people report that they cannot engage in a daydream if they are not listening to music (Jopp et al., 2019; Schimmenti et al., 2020). Physical and auditory stimulations probably play an important role in both MD and RS, especially when it comes to induction. It seems, however, that although the exposure to music in MD is usually related to one's musical tastes and serves as an emotionally evocative "soundtrack," in RS the music and sounds seem more connected with meditation-based audio or video guides, or ambient sounds associated with "subliminal" affirmations.
Reports by individuals who practice RS seldom describe associated negative emotions, except for expressed frustrations for being unable to reach the DR. In contrast, MD is a more secretive behavior, associated with distress and shame (Ferrante et al., 2020). Furthermore, although MD communities tend to focus on peer support for the control of excessive daydreaming, RS communities seem to emphatically encourage engagement in this activity. The emotional features of RS need to be investigated in detail.

The mental activity of RS clearly involves a highly immersive form of daydreaming. At this early state of inquiry, determining its location on the normal-abnormal dimension is premature. We maintain, however, that the inclusive category under which RS is best placed, is ID. Because individuals practicing RS claim to exercise controlled induction techniques to evoke the desired state of fantasy, we tend to place RS closer to the normal end of the ID spectrum (see Fig. 2). However, future research should determine if RS could be dimensional, in terms of mental health. In other words, like most psychological phenomena, RS might span from voluntary, controlled mentation to pathological fantasizing associated with distress or impairment.

\section{Relations with Associated Phenomena}

The differences between the various features of RS and related phenomena reviewed above are summarized in Table 1. According to our analysis, tulpamancy, hypnosis, and LD share many characteristics with RS, such as the importance of predisposition, induction, suggestions, training, and individual differences. DA and MD, a normal and a pathological variant of the same dimension, seem to be more distinct because of the lack of need for induction, suggestions, or training.

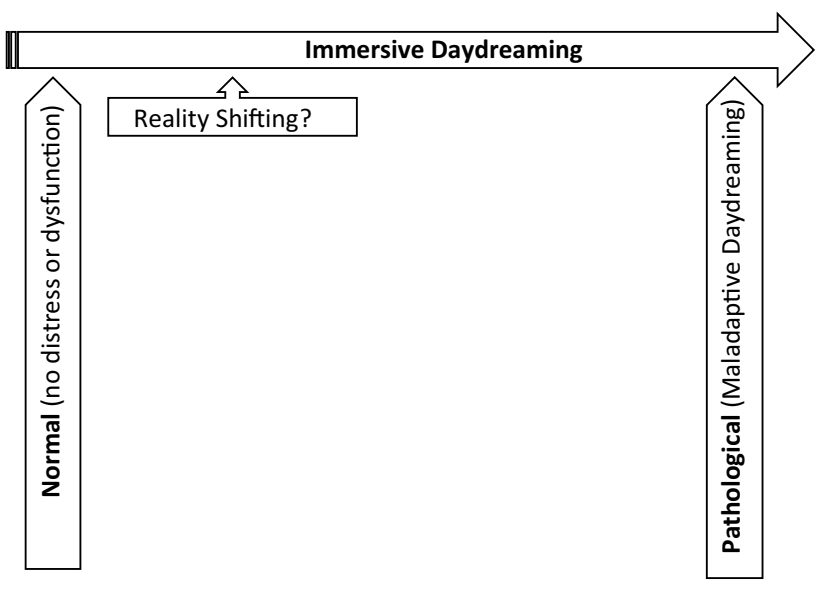

Fig. 2 A continuum of normal to pathological immersive daydreaming. Reality Shifting seems to be located on the normal side of the spectrum, although the existence of pathological variants cannot yet be excluded 
Table 1 A Comparison of Features of Reality Shifting (RS) and Related Phenomena

\begin{tabular}{|c|c|c|c|c|c|c|c|}
\hline \multirow[t]{2}{*}{ Features } & & \multicolumn{6}{|c|}{ Compared Phenomena } \\
\hline & & $\mathrm{RS}$ & Tulpa & Hypnosis & LD & DA & MD \\
\hline \multirow[t]{3}{*}{ Activation } & Induction & Yes & Yes & Yes & Yes & No & No \\
\hline & Suggestions & Yes & Yes & Yes & Yes & No & No \\
\hline & Training & Yes & Yes & Yes & Yes & No & No \\
\hline \multirow[t]{2}{*}{ Natural variation } & Predisposition & Likely & Likely & Yes & Likely & Yes & Yes \\
\hline & Individual differences & Yes & Yes & Yes & Yes & Yes & Yes \\
\hline Mind-body aspects & $\begin{array}{l}\text { Associated bodily phe- } \\
\text { nomena/ sensations }\end{array}$ & Yes & Unknown & Yes & No & No & Yes \\
\hline \multirow[t]{2}{*}{ Valence/ implications } & Positive & Yes & Yes & Yes & Yes & Likely & Yes \\
\hline & Negative & Unknown & Unknown & Uncommon & Uncommon & Yes & Yes \\
\hline
\end{tabular}

Note. $\mathrm{RS}=$ Reality Shifting; $\mathrm{LD}=$ Lucid Dreaming; DA = Dissociative Absorption; $\mathrm{MD}=$ Maladaptive Daydreaming

In addition, we suggest a theoretical model, presented in Fig. 2, outlining hypothesized etiological underpinnings of RS. As can be seen in the model, we propose that the successful implementation of RS stems from a combination of necessary individual differences traits (DA, hypnotizability, FP, and/or an ability for ID) and self-training using various techniques for RS induction reviewed earlier. Such selftraining is hypothesized to be influenced by: (1) cultural factors, such as social media influencers' endorsement of RS, and (2) the person's motivation and dedication to RS. This motivation is in turn also influenced by cultural factors (e.g., Harry Potter movies), and/or personal factors: either negative, like a wish to escape an adverse experience, or positive, like the need for a creative experience. Social stressors may be important to elicit some of these personally motivating factors. For example, it is well documented that the Covid19 pandemic, with its associated restrictions, had led to an increase in psychological distress and loneliness, in general and in young people specifically (e.g., Bu et al., 2020; Li and Wang, 2020). All these hypothesized influencing factors should be investigated in future empirical endeavors (Fig. 3).

\section{Benefits and Risks}

The global COVID-19 threat, and consequent imposition of social isolation measures seemed to be followed by a sudden emergence and steep rise of RS searches on Google. The emerging wide interest in this practice among young people in this context implies a possible connection between the two events. Evidence shows that people's mental health has been severely affected by the pandemic (Javed et al., 2020), resulting in a substantial increase in 2020 in Google search intensity for boredom, loneliness, worry, and sadness in Europe and the US (Brodeur et al., 2021). Furthermore, Gallup's Negative Experience Index, which annually tracks sadness, anger, worry, and stress worldwide in more than
100 countries and areas, showed that in 2020 the world was feeling the worst it had in 15 years (Ray, 2021). The contemporaneousness of the pandemic outbreak, the worldwide rise in negative feelings, and the emergence of RS imply that the global threat might have contributed to the swift appearance of an alternative, solitary mental activity, in line with similar elevations in maladaptive daydreaming observed recently (Somer et al., 2020).

Nonetheless, it is plausible that RS practice would have gained some prominence independently of COVID-19. Getting absorbed in counterfactual experiences, such as RS and MD, has been a source of enjoyment ever since humans started relating tales and myths to others, and explains part of the importance of the habit of reading for many people. Extrapolating from the scientific literature on tulpamancy, it seems likely that RS may also provide a sense of companionship with non-threatening beings and increase practitioners' sense of self-efficacy.

The effect of the online RS culture on its practitioners may be both socially supportive and stressful. The benefits of RS notwithstanding, there are also potential risks in RS, including a decreased sense of control of mental contents, as the following quotation exemplifies.

I'm not exactly sure what's wrong with me. Every time I try to take a break from trying to shift, I just can't. My DR seems to always be in the back of my mind. It's just like a dull itch that never goes away. I try to shift using a sleep method because it works best for me. When I lay [sic] in bed at night, my mind always tells me "you should try shifting tonight," even if I want to take a break. I feel like if I take a break, I'll come back feeling more refreshed and motivated, but my mind just won't let me. Does this even make sense? What do I do?

A similar risk has been pinpointed for excessive use of deliberate LD induction techniques, which may cause somewhat 
Fig. 3 Theoretical Model of Etiological Factors for Reality Shifting (RS)

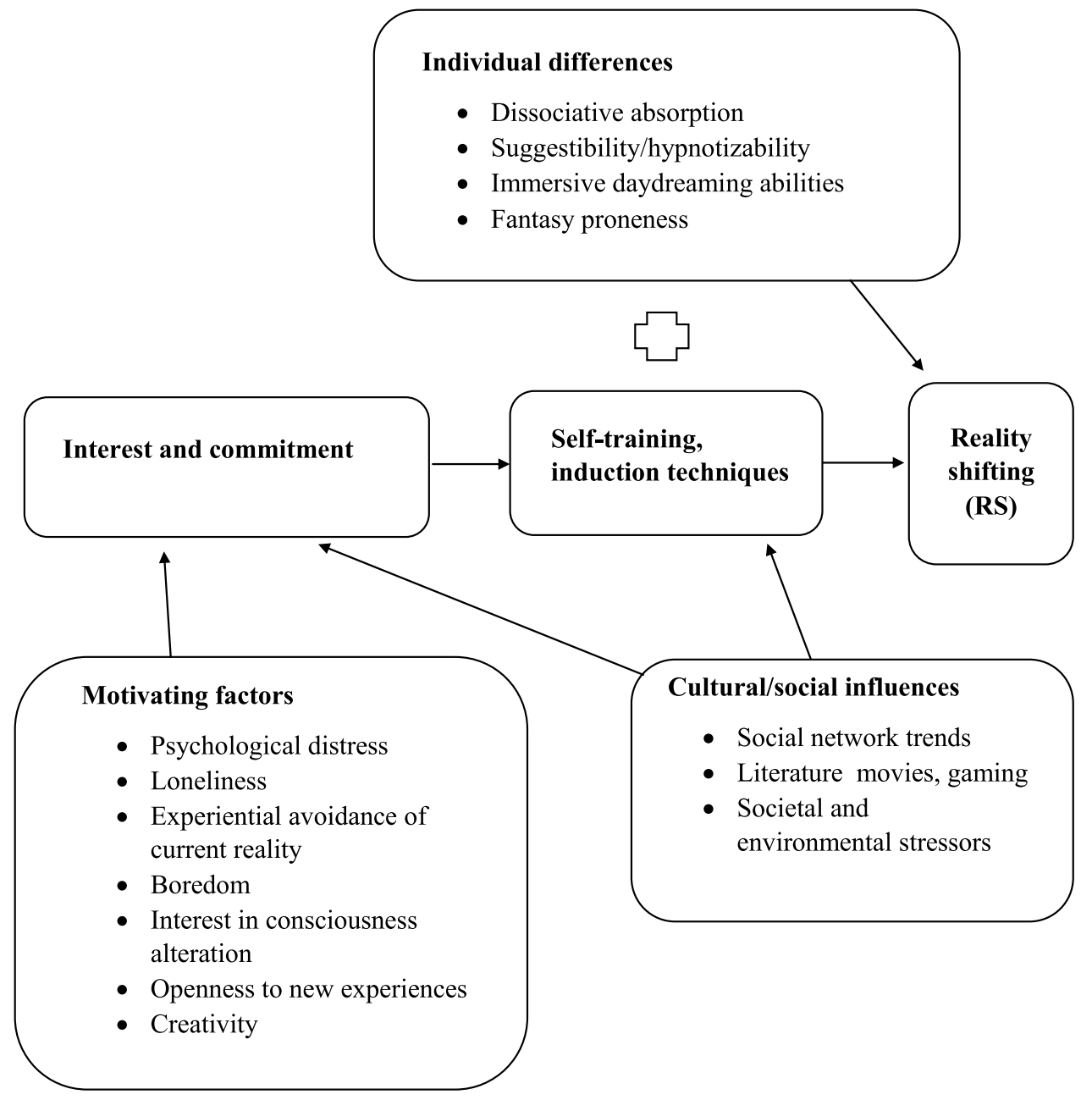

of a blurring of boundaries between waking and dreaming consciousness (Soffer-Dudek, 2020). In RS, this may be confounded by the notion of some practitioners' beliefs that their experiences involve creating literal alternate realities, rather than believed-in-imaginings. An investment in such practice at the expense of developing coping tasks to deal with real-life challenges such as social anxiety and loneliness may be deleterious. Also, some people with MD report its addictive component, which lessens their ability to control the experience. Future research should determine whether RS practice can lead to $\mathrm{MD}$, thus causing functional impairment.

\section{Summary and Recommendations for Future Research}

This may be the first scholarly description of reality shifting, a newly growing trend involving imaginal immersions employed mostly by teenagers and very young adults. Although the self-reported experience of volitional self-transportation into a parallel reality is unusual, we showed its resemblance to other mental activities involving intense engagement in vivid fantasy. The common denominator connecting these powerful and emotionally compelling anomalous experiences seems to involve alterations of consciousness via absorption into counterfactual realities achieved through hypnotic-like procedures.

$\mathrm{RS}$ is a deliberate, absorptive, and rewarding alteration of consciousness induced by hypnotic-like procedures. The absorptive skills developed in RS, ID, and tulpamancy might be relevant as emotion regulation and stress management coping strategies in some psychotherapy processes. The potential benefits and risks of this newly identified trend call for systematic research. Many questions concerning the profile of typical "shifters" are open for investigation, including demographic variables, psychological and physical health status, and explorations of RS in relation to the constructs discussed in this paper. Qualitative research could shed light on the phenomenology of RS, including its meaning to practitioners, its emotional features, and psychological underpinnings and functions. Studies are needed to assess its 
potential adaptive and pathological variants through longitudinal designs that follow up novice practitioners throughout their RS practice and evaluate diverse trajectories and their consequences.

\section{Declarations}

Data sharing not applicable to this article as no datasets were generated or analyzed.

The authors declare no conflict of interest.

The study involved publicly available data and required no IRB review or the administration of an informed consent.

\section{References}

peachy, (2019) . Lifa App. Retrieved July 7, 2021, from https://amino apps.com/c/idealreality 12/page/blog/lifa-app/P4m7_MbImu NQ4ovv27Vq71RzB4Mqv1ljxK.

Andrews, T.M. (2021). Inside 'reality shifting,' the trend where TikTokers claim they can enter the world of Harry Potter. Washington Post. https://www.washingtonpost.com/technology/2021/07/17/ reality-shifting-tiktok/,

Aviram, L., \& Soffer-Dudek, N. (2018). Lucid dreaming: Intensity, but not frequency, is inversely related to psychopathology. Frontiers in Psychology, 9, 384. https://doi.org/10.3389/fpsyg.2018.00384

Barber, T. X. (1984). Changing "unchangeable" bodily processes by (hypnotic) suggestions. In A. A. Sheikh (Ed.), Imagination and healing (pp. 69-127). Baywood.

Barnier, A. J., \& Council, J. R. (2010). Hypnotizability matters: The what, why, and how of measurement. In S. J. Lynn, J. W. Rhue \& I. Kirsch (Eds.), Handbook of clinical hypnosis (2nd ed., pp. 47-77). American Psychological Association.

Barrow, J., Davies, P., \& Harper, Jr C, (Eds.). (2004). Science and ultimate reality: Quantum theory, cosmology, and complexity. Cambridge University Press. doi: 10.1017/CBO9780511814990.

Bartholomew, R. E., Basterfield, K., \& Howard, G. S. (1991). UFO abductees and contactees: psychopathology or fantasy proneness? Professional Psychology: Research and Practice, 22(3), 215-222. https://doi.org/10.1037/0735-7028.22.3.215

Bentall, R. P. (2014). Hallucinatory experiences. In E. Cardeña, S.J. Lynn, \& S. Krippner (Eds.), Varieties of anomalous experience: Examining the scientific evidence (2nd ed., pp. 109-144). American Psychological Association.

Bernini, M. (2018). Affording innerscapes: Dreams, introspective imagery and the narrative exploration of personal geographies. Frontiers of Narrative Studies, 4(2), 291-311. https://doi.org/10. 1515/fns-2018-0024

Bigelsen, J., Lehrfeld, J. M., Jopp, D. S., \& Somer, E. (2016). Maladaptive daydreaming: Evidence for an under-researched mental health disorder. Consciousness and Cognition, 42, 254-266. https://doi. org/10.1016/j.concog.2016.03.017

Borges, J. L. (1997). Las ruinas circulares [the circular ruins]. In Ficciones (fictions), pp. 56-65. Alianza editorial. (originally published 1944).

Bregman-Hai, N., Abitbul-Gordon, S., Deutsch, I., Garbi, D., Shelef, L., \& Soffer-Dudek, N. (2018). Leave everything to the imagination: Cognitive functioning of individuals high in dissociative absorption and imaginative involvement. Journal of Research in Personality, 76, 129-138. https://doi.org/10.1016/j.jrp.2018.08. 004

Bregman-Hai, N., Kessler, Y., \& Soffer-Dudek, N. (2020). Who wrote that? Automaticity and reduced sense of agency in individuals prone to dissociative absorption. Consciousness \& Cognition, 78, 102861. https://doi.org/10.1016/j.concog.2019. 102861

Brodeur, A., Clark, A. E., Fleche, S., \& Powdthavee, N. (2021). COVID-19, lockdowns and well-being: Evidence from Google trends. Journal of Public Economics, 193, 104346. https://doi. org/10.1016/j.jpubeco.2020.104346

Bu, F., Steptoe, A., \& Fancourt, D. (2020). Who is lonely in lockdown? Cross-cohort analyses of predictors of loneliness before and during the COVID-19 pandemic. Public Health, 186 , 31-34. https://doi.org/10.1016/j.puhe.2020.06.036

Cardeña, E. (2005). The phenomenology of deep hypnosis: Quiescent and physically active. International Journal of Clinical and Experimental Hypnosis, 53(1), 37-59. https://doi.org/10.1080/ 00207140490914234

Cardeña, E., \& Alvarado, C. (2014). Anomalous self and identity experiences. In E. Cardeña, S. J., Lynn, \& S. Krippner (Eds.), Varieties of anomalous experience: Examining the scientific evidence (2nd ed., pp. 175-212). American Psychological Association.

Cardeña, E., \& Terhune, D. (2009). A note of caution on the Waterloo Stanford group scale of hypnotic susceptibility: A brief communication. International Journal of Clinical and Experimental Hypnosis, 57, 222-226. https://doi.org/10.1080/00207140802665484

Cardeña, E., \& Terhune, D. B. (2014). Hypnotizability, personality traits and the propensity to experience alterations of consciousness. Psychology of Consciousness: Theory, Research, and Practice, 1(3), 292-307. https://doi.org/10.1037/cns0000026

Carlson, E. B., \& Putnam, F. W. (1993). An update on the dissociative experiences scale. Dissociation, 6, 16-27. Retrieved July 7, 2021, from http://hdl.handle.net/1794/1539

David-Neel, A. (1971). Magic and mystery in Tibet. Dover. (originally published 1929).

de Rivera, J., \& Sarbin, T. R. (1998). Believed-in imaginings: The narrative construction of reality. American Psychological Association.

Dorsch, F. (2015). Focused daydreaming and mind-wandering. Review of Philosophy and Psychology, 6(4), 791-813. https://doi.org/10. 1007/s13164-014-0221-4S

Dresler, M., Wehrle, R., Spoormaker, V. I., Koch, S. P., Holsboer, F., Steiger, A., Obrig, H., Sämann, P. G., \& Czich, M. (2012). Neural correlates of dream lucidity obtained from contrasting lucid versus non-lucid REM sleep: A combined EEG/fMRI case study. Sleep, 35, 1017-1020. https://doi.org/10.5665/sleep.1974

Fernyhough, C., Watson, A., Bernini, M., Moseley, P., \& AldersonDay, B. (2019). Imaginary companions, inner speech, and auditory verbal hallucinations: What are the relations? Frontiers in Psychology, 10, 1665. https://doi.org/10.3389/fpsyg.2019.01665

Ferrante, E., Marino, A., Guglielmucci, F., \& Schimmenti, A. (2020). The mediating role of dissociation and shame in the relationship between emotional trauma and maladaptive daydreaming. Psychology of Consciousness: Theory, Research, and Practice. doi: $10.1037 / \mathrm{cns} 0000253$.

Filevich, E., Dresler, M., Brick, T. R., \& Kühn, S. (2015). Metacognitive mechanisms underlying lucid dreaming. Journal of Neuroscience, 35, 1082-1088. https://doi.org/10.1523/JNEUROSCI.3342-14.2015

Hammond, C. (Ed.). (1988). Hypnotic induction \& suggestion: An introductory manual. American Society of Clinical Hypnosis.

Hartland, J. (1971). Further observations on the use of "ego-strengthening" techniques. American Journal of Clinical Hypnosis, 14(1), 1-8. https://doi.org/10.1080/00029157.1971.10402136

Holt, N. J., Simmonds-Moore, C., \& Moore, S. L. (2020). Does latent inhibition underpin creativity, positive schizotypy, and anomalous cognition? Journal of parapsychology, 84(2), 156-178. Doi: 10.30891/jopar2020.02.02.

Isler, J. J. (2017). Tulpas and mental health: A study of non-traumagenic plural experiences. Research in psychology and behavioral sciences, 5(2), 36-44. Doi: 10.12691/rpbs-5-2-1. 
Javed, B., Sarwer, A., Soto, E. B., \& Mashwani, Z. U. (2020). The coronavirus (COVID-19) pandemic's impact on mental health. The International Journal of Health Planning and Management, 35(5), 993-996. https://doi.org/10.1002/hpm.3008

Johnson, C. R. (2020). The art of lucid dreaming: Over 60 powerful practices to help you wake up in your dreams. Llewellyn Worldwide.

Jopp, D. S., Dupuis, M., Somer, E., Hagani, N., \& Herscu, O. (2019). Validation of the Hebrew version of the maladaptive daydreaming scale (MDS-H): Evidence for a generalizable measure of pathological daydreaming. Psychology of Consciousness: Theory, Research, and Practice, 6(3), 242-261. https://doi.org/10.1037/ cns0000162

Kihlstrom, J. F. (2017). Tellegen Absorption Scale: Factors and content categories. Retrieved July 7, 2021, from https://www.ocf.berkeley. edu/ jfkihlstrom/TAS.htm.

Klinger, E. (2009). Daydreaming and fantasizing: Thought flow and motivation. In K. D. Markman, W. M. P. Klein, \& J. A. Suhr (Eds.), Handbook of imagination and mental simulation (pp. 225-239). Psychology Press.

Kosslyn, S. M., Thompson, W. L., Costantini-Ferrando, M. F., Alpert, N. M., \& Spiegel, D. (2000). Hypnotic visual illusion alters color processing in the brain. American Journal of Psychiatry, 157(8), 1279-1284. https://doi.org/10.1176/appi.ajp.157.8.1279

Kragh, H. (2009). Contemporary history of cosmology and the controversy over the multiverse. Annals of Science, 66(4), 529-551. https://doi.org/10.1080/00033790903047725

LaBerge, S. (2009). Lucid dreaming: A concise guide to awakening in your dreams and in your life: Easyread super large 24pt edition. ReadHowYouWant.com.

LaBerge, S. (2014). Lucid dreaming: Paradoxes of dreaming consciousness. In E. Cardeña, S. J. Lynn, \& S. Krippner (Eds.), Varieties of anomalous experience: Examining the scientific evidence (2nd ed., pp. 145-173). American Psychological Association.

LaBerge, S., \& Rheingold, H. (1990). Exploring the world of lucid dreaming. Ballantine.

Laursen, C. (2019). Plurality through imagination: The emergence of online tulpa communities in the making of new identities. In S. Natale, S. \& D. Pasulka (Eds.), Believing in bits: Digital media and the supernatural (pp. 163-179). Oxford Scholarship Online. doi: 10.1093/oso/9780190949983.003.0010.

Leviathan. (2020). You shifted [video]. YouTube. Retrieved July 7, 2021, from https://www.youtube.com/watch?v=Ya4IDPxKhRA

Li, L. Z. L., \& Wang, S. (2020). Prevalence and predictors of general psychiatric disorders and loneliness during COVID-19 in the United Kingdom. Psychiatry Research, 291, 113267. https://doi. org/10.1016/j.psychres.2020.113267

Linde, A. (2017). A brief history of the multiverse. Reports on Progress in Physics, 80(2), 022001. https://doi.org/10.1088/13616633/aa50e4

Lovi, M.. (2003, February). Respawning guide. Retrieved July 7, 2021, from https://aminoapps.com/c/realityshifting/page/blog/respa wning-guide/o33N_gqafduw05vb2p8gZDP60lkwr3qnjJCG

Marcusson-Clavertz, D., \& Kjell, O. N. E. (2019). Psychometric properties of the spontaneous and deliberate mind wandering scales. European Journal of Psychological Assessment, 35(6), 878-890. https://doi.org/10.1027/1015-5759/a000470

McDonnel, W.M. (1983). The Gateway Experience: Brain hemisphere synchronization in perspective. Retrieved July 7, 2021, from https://www.cia.gov/readingroom/docs/CIA-RDP96-00788 R001700210016-5.pdf

McLewin, A., \& Muller, R. T. (2006). Childhood trauma, imaginary companions, and the development of pathological dissociation. Aggression and Violent Behavior, 11(5), 531-545. https://doi.org/ 10.1016/j.avb.2006.02.001
Merkelbach, H., Otgaar, H., \& Lynn, S. J. (2021). Empirical research on fantasy proneness and its correlates 2000-2018: A meta-analysis. Psychology of Consciousness: Theory, Research, and Practice. https://doi.org/10.1037/cns0000272

Moskowitz, A., Dorahi, M. J., \& Schäfer, I. (2018). Psychosis, trauma and dissociation: Evolving perspectives on severe psychopathology (2nd ed.). Wiley. https://doi.org/10.1080/15299732.2020.1787086

Natale, S., \& Pasulka, D. (2019). Believing in bits: Digital media and the supernatural. Oxford Scholarship Online.

Paulsson, T., \& Parker, A. (2006). The effects of a two-week reflection-intention training program on lucid dream recall. Dreaming, 16(1), 22-35. https://doi.org/10.1037/1053-0797.16.1.22

Pax, (2020). Desired reality - Amino. Retrieved July 7, 2021, from www.pinterest.com/pin/648870258812036619

Piccione, C., Hilgard, E. R., \& Zimbardo, P. (1989). On the degree of stability of measured hypnotizability over a 25 -year period. Journal of Personality and Social Psychology, 56(2), 289-295. https://doi.org/10.1037//0022-3514.56.2.289

Price R. F., \& Cohen D. B. (1988) Lucid dream induction. In J. Gackenbach \& S. LaBerge (Eds.), Conscious mind, sleeping brain (pp. 105134). Springer. doi: https://doi.org/10.1007/978-1-4757-0423-5_6.

Ray, J. (2021). 2020 sets records for negative emotions. Gallup. https:// news.gallup.com/poll/352205/2020-sets-records-negative-emoti ons.aspx

Reddit (n.d.). r/DimensionJumping. Retrived July 7, 2021, from https:// www.reddit.com/r/DimensionJumping/

Roche, S. M., \& McConkey, K. M. (1990). Absorption: Nature, assessment, and correlates. Journal of Personality and Social Psychology, 59(1), 91-101. https://doi.org/10.1037/0022-3514.59.1.91

Schädlich, M., \& Erlacher, D. (2012). Applications of lucid dreams: An online study. International journal of dream research, 5(2), 134-138. Doi: 10.11588/ijodr.2012.2.9505.

Schimmenti, A., Sideli, L., La Marca, L., Gori, A., \& Terrone, G. (2020). Reliability, validity, and factor structure of the maladaptive daydreaming scale (MDS-16) in an Italian sample. Journal of Personality Assessment, 102(5), 689-701. https://doi.org/10. 1080/00223891.2019.1594240

Schooler, J. W., Smallwood, J., Christoff, K., Handy, T. C., Reichle, E. D., \& Sayette, M. A. (2011). Meta-awareness, perceptual decoupling, and the wandering mind. Trends in Cognitive Science, 15, 319-326. https://doi.org/10.1016/j.tics.2011.05.006

Soffer-Dudek, N. (2020). Are lucid dreams good for us? Are we asking the right question? A call for caution in lucid dream research. Frontiers in Neuroscience, 13, 1423. https://doi.org/10.3389/fnins. 2019.01423

Soffer-Dudek, N., \& Somer, E. (2018). Trapped in a daydream: Daily elevations in maladaptive daydreaming are associated with daily psychopathological symptoms. Frontiers in Psychiatry, 9, 194. https://doi.org/10.3389/fpsyt.2018.00194

Soffer-Dudek, N., \& Somer, E. (in press). Maladaptive daydreaming is a dissociative disorder: Supporting evidence and theory. In M. Dorahy \& S. Gold (Eds.), Dissociation and the dissociative disorders: Past, present, future (2nd ed.). Routledge.

Soffer-Dudek, N., Lassri, D., Soffer-Dudek, N., \& Shahar, G. (2015). Dissociative absorption: An empirically unique, clinically relevant, dissociative factor. Consciousness and Cognition, 36, 338-351. https://doi.org/10.1016/j.concog.2015.07.013

Soffer-Dudek, N., Somer, E., Abu-Rayya, H. M., Metin, B., \& Schimmenti, A. (2021). Different cultures, similar daydream addiction? An examination of the cross-cultural measurement equivalence of the maladaptive daydreaming scale. Journal of Behavioral Addictions, 9(4), 1056-1067. https://doi.org/10.1556/2006.2020.00080

Somer, E. (2002). Maladaptive daydreaming: A qualitative inquiry. Journal of Contemporary Psychotherapy, 32(2/3), 197-212. https://doi.org/10.1023/A:1020597026919 
Somer, E., Abu-Rayya, H. M., Schimmenti, A., Metin, B., Brenner, R., Ferrante, E., Göçmen, B., \& Marino, A. (2020). Intensified maladaptive daydreaming is associated with COVID-19 social distancing, pre-existing psychiatric diagnoses, and worsening of psychological dysfunction indices in a large multi-country sample. Frontiers in Psychiatry, 11, 587455. https://doi.org/10.3389/fpsyt. 2020.587455

Somer, E., Abu-Rayya, H. M., \& Brenner, R. (2021). Childhood trauma and maladaptive daydreaming: Fantasy functions and themes in a multi-country sample. Journal of Trauma \& Dissociation, 22(3), 288-303. https://doi.org/10.1080/15299732.2020.1809599

Somer, E., Soffer-Dudek, N., \& Ross, C. A. (2017). The comorbidity of daydreaming disorder (maladaptive daydreaming). Journal of Nervous and Mental Disease, 205(7), 525-530. https://doi.org/10. 1097/NMD.0000000000000685

Song, X., \& Wang, X. (2012). Mind wandering in Chinese daily lives: An experience sampling study. PLoS One, 7(9), e44423. https:// doi.org/10.1371/journal.pone.0044423

Spiegel, H. (1974). The grade 5 syndrome: The highly hypnotizable person. International Journal of Clinical and Experimental Hypnosis, 22(4), 303-319. https://doi.org/10.1080/002071474084130 10

Stawarczyk, D. (2018). Phenomenological properties of mind-wandering and daydreaming: A historical overview and functional correlates. In K. Christoff and K. C. R. Fox. (Eds), The Oxford handbook of spontaneous thought: Mind-wandering, creativity, and dreaming. Oxford Handbooks Online. DOI: 10.1093/oxfor $\mathrm{dhb} / 9780190464745.013 .18$.

Stendel, M., Ramstead, M., \& Veissière, S. (2020). Internet sociality. In L. Kirmayer, C. Worthman, S. Kitayama, R. Lemelson, \& C. Cummings (Eds.), Culture, mind, and brain: Emerging concepts, models, and applications (pp. 461-476). Cambridge University Press. doi: https://doi.org/10.1017/9781108695374.026.

Tellegen, A. (1992). Note on structure and meaning of the MPQ Absorption scale. Unpublished manuscript, University of Minnesota

Tellegen, A., \& Atkinson, G. (1974). Openness to absorbing and selfaltering experiences ("absorption"), a trait related to hypnotic susceptibility. Journal of Abnormal Psychology, 83(3), 268-277. https://doi.org/10.1037/h0036681

Terhune, D. B., \& Cardeña, E. (2010). Differential patterns of spontaneous experiential response to a hypnotic induction: A latent profile analysis. Consciousness and Cognition, 19(4), 1140-1150. https://doi.org/10.1016/j.concog.2010.03.006

Terhune, D. B., Cardeña, E., \& Lindgren, M. (2010). Dissociative tendencies and individual differences in high hypnotic suggestibility. Cognitive Neuropsychiatry, 16(2), 113-135. https://doi.org/10. 1080/13546805.2010.503048

TikTok (n.d.-a). \#realityshifting. Retrieved July 7, 2021, from https:// www.tiktok.com/tag/realityshifting?lang=en.

TikTok (n.d.-b) \#shiftinfgrealities. Retrieved July 7, 2021, from https:// www.tiktok.com/tag/realityshifting?lang=en.

u/Automoderator, (2021). Start here. Retrieved July 7, 2021, from https://www.reddit.com/r/shiftingrealities/comments/mn86d1/ start_here/?utm_source $=$ share \&utm_medium $=$ web $2 x \&$ conte $\mathrm{xt}=3$.

Veissière, S. (2016). Varieties of Tulpa experiences: Sentient imaginary friends, embodied joint attention, and hypnotic sociality in a wired world. In A. Raz \& M. Lifshitz (Eds). Hypnosis and meditation: Towards an integrative science of conscious planes (pp. 55-75). Oxford University Press.

Voss, U., D'Agostino, A., Kolibius, L., Klimke, A., Scarone, S., \& Hobson, J. A. (2018). Insight and dissociation in lucid dreaming and psychosis. Frontiers in Psychology, 12, 2164. https://doi.org/ 10.3389/fpsyg.2018.02164

Voss, U., Holzmann, R., Hobson, A., Paulus, W., Koppehele-Gossel, J., Klimke, A., \& Nitsche, M. A. (2014). Induction of self-awareness in dreams through frontal low current stimulation of gamma activity. Nature Neuroscience, 17, 810-812. https://doi.org/10.1038/ nn.3719

Voss, U., Holzmann, R., Tuin, I., \& Hobson, J. A. (2009). Lucid dreaming: A state of consciousness with features of both waking and non-lucid dreaming. Sleep, 32, 1191-1200. https://doi.org/10. 1093/sleep/32.9.1191

West, M. J., \& Somer, E. (2020). Empathy, emotion regulation, and creativity in immersive and maladaptive daydreaming. Imagination, Cognition and Personality, 39(4), 358-373. https://doi.org/ 10.1177/0276236619864277

Wilson, S. C., \& Barber, T. X. (1982). The fantasy-prone personality: Implications for understanding imagery, hypnosis, and parapsychological phenomena. PSI Research, 1(3), 94-116.

Publisher's Note Springer Nature remains neutral with regard to jurisdictional claims in published maps and institutional affiliations. 